\title{
Construction and validation of the Scale of Perceived Gains from High-Fidelity Simulation (Escala de Ganhos Percebidos com a Simulação de Alta Fidelidade - EGPSA)
}

\author{
Construção e validação da Escala de Ganhos Percebidos com a Simulação de Alta-Fideli- \\ dade (EGPSA) \\ Construcción y validación de una escala de beneficios percibidos con la simulación de \\ alta-fidelidad (Escala de Ganhos Percebidos com a Simulação de Alta Fidelidade - EGPSA) \\ Rui Carlos Negrão Batista*; José Carlos Amado Martins**; Maria Fátima Carneiro Ribeiro Pereira***
}

\begin{abstract}
Background: When used as a teaching strategy, high-fidelity simulation makes students feel more motivated, self-confident, interested and engaged in the learning process, preparing them for real-life situations.

Objectives: To validate an instrument used to assess students' perception of the gains from high-fidelity simulation practices.

Methodology: This was a methodological research study, with the application of a 26-item scale to a convenience sample of 458 nursing students after their participation in simulated practices. Construct validity was assessed through exploratory factor analysis with Varimax orthogonal rotation and confirmed through sample randomization and internal consistency analysis.

Results: High item-total correlations were found in almost all items of the scale, which had an alpha value of .951. Reliability analysis of the five factors shows an internal consistency ranging from .699 to .930 .

Conclusion: The scale meets the validity requirements, and has significant potential to be used in research.
\end{abstract}

Keywords: nursing students; simulation; education, nursing

\section{Resumo}

Enquadramento: A simulação de alta-fidelidade enquanto estratégia de ensino permite que o estudante se sinta mais motivado, autoconfiante, interessado e envolvido na sua aprendizagem, preparando-o para o contexto real.

Objetivos: Validar instrumento de avaliação dos ganhos percebidos pelos estudantes de enfermagem com práticas simuladas de alta-fidelidade.

Metodologia: Estudo de investigação metodológica. Aplicada escala de 26 itens a uma amostra de conveniência de 458 estudantes de enfermagem, após práticas simuladas. Realizado estudo da validade de constructo pela análise fatorial com rotação ortogonal varimax e validação com recurso à randomização de amostras e a estimativa da consistência interna.

Resultados: A escala apresenta elevada correlação de praticamente todos os itens com o total da escala, com um Alpha de 0,951. A análise da fidelidade dos 5 fatores apresenta uma consistência interna entre 0,699 e 0,930.

Conclusão: A escala cumpre os requisitos de validade, revelando elevado potencial para utilização em investigação.

Palavras-chave: estudantes de enfermagem; simulação; educação em enfermagem

\footnotetext{
* MSc., Adjunct Professor, Nursing School of Coimbra, 3046-851 Coimbra, Portugal [ruib@esenfc. pt]. Contribution to the article: literature search; data collection; statistical treatment and analysis; data analysis and discussion; article writing. Address for correspondence: Rua 5 de Outubro, 41 A, Cimo de Fala, São Martinho do Bispo, 3046-851, Coimbra, Portugal.

Cimo de Fala, São Martinho do Bispo, 3046-851, Coimbra, Portugal. ** PhD, Assistant Professor, Faculty of Psychology and Education Sciences, University of Porto,
4169-004, Porto, Portugal [fpereira@fpce.up.pt]. Contribution to the article: literature search, statistical treatment and analysis, data analysis and discussion; article writing.

*** PhD, Coordinating Professor, Nursing School of Coimbra, 3046-851, Coimbra, Portugal [jmartins@esenfc.pt]. Contribution to the article: literature search; data collection; statistical
} treatment and analysis; data analysis and discussion; article writing.

\section{Resumen}

Marco contextual: La simulación de alta fidelidad como estrategia de enseñanza permite que el estudiante se sienta más motivado, seguro de sí mismo, interesado y participativo en su aprendizaje, lo prepara para el contexto real.

Objetivos: Validar instrumento para evaluar las ganancias percibidas por los estudiantes de enfermería con práctica simulada de alta-fidelidad.

Metodología: Estudio de investigación metodológica. Aplicada escala de 26 ítems a una muestra de conveniencia de 458 estudiantes de enfermería después de práctica simulada. Se realizó estudio de la validez de constructo mediante el análisis factorial con rotación varimax y su validación, mediante la randomización de las muestras y estimación de la consistencia interna.

Resultados: La escala presenta alta correlación de casi todos los ítems con la escala total, con un alfa de 0.951. El análisis de la fidelidad de los cinco factores muestra una consistencia interna entre 0.699 y 0.930 .

Conclusión: La escala cumple los requisitos de validez, dejando al descubierto un gran potencial para su uso en investigación.

Palabras clave: estudiantes de enfermería; simulación; educación en enfermería

Received for publication: 29.12 .15

Accepted for publication: 13.06 .16 


\section{Introduction}

From an early stage in nursing education, the simulation of key procedures for professional practice in a controlled environment and in the patients' absence has shown to improve the students' performance in the actual context, not only at the technical level, but also at the psychological, cognitive, and attitudinal levels. The previous simulation of clinical experiences contributes to improving nursing students' satisfaction with their learning and confidence in their abilities (Swenty \& Eggleston, 2010).

In real-life situations, one of the most stressful situations for students concerning care provision are those related to the fear of making mistakes, harming others, feeling incompetent in their performance, not knowing how to clarify the patients' doubts, and what to do and how to act in situations related to the therapeutic regimen and professional relationships (Butler, Veltre, \& Brady, 2009). The evidence suggests that high levels of stress hinder an effective performance, and whenever students feel afraid and/ or question their capabilities, their clinical judgment and reasoning are affected (Barroso, Vilela, \& Rainho, Correia, \& Antunes, 2008).

This study aims at validating a scale with the potential for assessing nursing students' perception of the gains achieved after their clinical experience using high-fidelity simulators.

\section{Background}

Simulation centers, equipped with realistic materials and equipment, are increasingly capable of replicating the whole clinical environment, allowing students to practice as many times as necessary and without the fear of making mistakes or compromising the patient's safety. This helps students to feel confident in their ability to care for a real patient and be integrated in a multidisciplinary health team.

As a teaching and learning strategy that attempts to replicate real environments (Teixeira \& Felix, 2011), high-fidelity simulation helps students to improve their communication skills, feel more confident in their own abilities, develop critical thinking skills (Kameg, Howard, Clochesy, Mitchell, \& Suresky,
2010), and improve their clinical judgment and ability to reflect on their practice (Martins et al., 2012; Sanford, 2010).

For this purpose, nursing schools have invested in this new teaching-learning strategy so that their students are able to have quality simulated clinical experiences, with different levels of complexity and fidelity, using resources that incorporate the latest technologies. These features allow students to feel confident about their skills and understand the usefulness and application of what they have learned in the clinical context (Kelly, 2014; Martins et al., 2012). Students have a positive perception of modern technologies (Montenery et al., 2013), and their integration into the teaching process promotes the student's learning, motivation, interest, and participation (Flo, Flaathen, \& Fagerström, 2013; Karagozoqu, 2009)

Perceptions are multifaceted and translate into evaluations of objects, which may vary according to positive or negative dimensions (Fabrigar, Macdonald, \& Wegener, 2005). Perceptions can be considered as one of the main components of the cognitive domain of attitude. The perceived personal gains from simulated clinical experiences are translated into the students' attitude toward the patients and the situations that they experience, and the impact of their behavior on the assessment and decision-making processes.

The students' perceptions of their abilities are influenced by their own social representations, thus by the meaning that they assign to their experiences within the academic environment. By documenting the students' perceptions of the simulated experiences, nursing schools can improve the effectiveness of these experiences and validate their applicability in the actual context (Holli, 2015).

\section{Research questions}

Based on the assumption that knowledge production requires the operationalization of concepts into empirically observable variables, and considering that gains are difficult to measure through direct observation, we formulated the following research question to guide this study: how can we measure the gains perceived by students after simulated clinical experiences using with high-fidelity simulators? 


\section{Methodology}

This is an analytical and methodological research study with a quantitative approach.

\section{Study participants}

We used a convenience sample composed of $4^{\text {th }}$-year students of the Bachelor's Degree in Nursing who, after 18 theoretical-practical hours and 18 practical hours within the Curricular Unit of Emergency Nursing, participated in simulated practices using high-fidelity simulators (adult Stan $^{\circledR}$ and pediatric PediaSim ${ }^{\circledR}$ ) in a laboratory with realistic materials and facilities.

\section{Data collection}

At the end of the Curricular Unit of Emergency Nursing, the students were invited to participate in the study by answering a questionnaire. The students were informed of the study purpose and the anonymous and voluntary nature of their participation.

\section{Ethical aspects}

The study was authorized by the institution and approved by the Ethics Committee of the Health Sciences Research Unit: Nursing, hosted by the Nursing School of Coimbra (P 01-09/2010). In order not to hinder questionnaire completion, we conducted the study after students had made their final assessment of the curricular unit. The research participants signed an informed consent form.

\section{Data analysis}

After data collection, we used the SPSS ${ }^{\circledR}$ (Statistical Package for the Social Sciences) software, version 19 for Windows to create a database which allowed us to characterize the sample and analyze the validity and reliability of the scale. For the purpose of analyzing the results, $p<.05$ was considered to be statistically significant.

In order to ensure the best results for this study, we considered a minimum ratio of 10 participants per each scale item to be analyzed (Hair, Black, Babin, \& Anderson, 2010).

\section{Process of scale construction}

The scale was designed and validated based on a theoretical framework and on a previous systematic review conducted on the topic (Baptista, Martins, Pereira, \& Mazzo, 2014), which resulted in a list of 30 variables. It is a Likert-type scale composed of 30 statements in which students express their opinion through five response options: I got worse, I stayed the same, I improved a little, I improved considerably and I improved a great deal. The different variables identify the students' perceptions of the gains achieved using high-fidelity simulators in simulated clinical experiences, at the cognitive, practical, reflective, relational and attitudinal levels.

After a pre-test with 18 students who were not included in the study, we concluded that four out of the 30 variables were not easy to understand and could raise doubts when completing the questionnaire. Thus, these four variables were removed. The final scale Scale of Perceived Gains from High-Fidelity Simulation (Escala de Ganbos Percebidos com a Simulação de Alta-Fidelidade - EGPSA) - is composed of 26 items (Table 1).

Table 1

Identification of the EGPSA variables

\begin{tabular}{ll}
\hline Variables & Designation of the variable \\
\hline 1 & Theoretical knowledge \\
2 & Overall impact on learning \\
3 & Ability to mobilize knowledge \\
4 & Recognizing signs and symptoms of severity \\
5 & Assessment of the critically ill patient \\
6 & Decision-making in a critical situation \\
7 & Disciplined and structured thinking \\
8 & Ability to diagnose priority needs \\
9 & Definition of priorities in an emergency situation \\
10 & Ability to provide a structured intervention in an emergency situation \\
11 & Solving problems in complex settings
\end{tabular}




\begin{tabular}{ll}
12 & Elaborating an action plan in an emergency situation \\
13 & Developing interventions related to airway management \\
14 & Developing interventions related to ventilation \\
15 & Develop interventions related to circulation \\
16 & Developing interventions related to the neurological function \\
17 & Leadership in an emergency situation \\
18 & Assessing the results of implemented actions \\
19 & Self-confidence \\
20 & Reflection on action \\
21 & Self-criticism \\
22 & Ability to use emergency-specific materials and equipment \\
23 & Use of emergency-specific equipment \\
24 & Psychomotor abilities related to emergency interventions \\
25 & Speed of reasoning in complex settings \\
26 & Effective response time in an emergency situation \\
\hline
\end{tabular}

\section{Results}

\section{Sample}

The sample was composed of 458 students who volunteered for the study after having participated in scenarios using high-fidelity simulators.

Most respondents (79.50\%) are women aged between 20 and 38 years (mean of 22.1 years, mode of 21 years and standard deviation of 1.8 years).

Most students (96.30\%) reported having actively participated in scenarios using high-fidelity simulators, whereas the remaining students reported having participated as observers of those practices.

\section{Validity and reliability of the scale}

The database proved to be adequate regarding the number of cases and their association with the number of variables. Using the correlation matrix, the inter-variable correlation showed a very good linear association between variables, in which $95 \%$ of correlations were greater than .30 and all the variables had significant correlations, $p<.001$. With regard to sampling adequacy, the scale showed a value of .946 in the Kaiser-Meyer-Olkin test, and $X^{2}=7257.416$ with $p<.001$ in the Bartlett's test of sphericity. These results suggest that data were adequate to the factor analysis. The anti-image correlation matrix corroborated the sampling adequacy of each variable in order to use factor analysis, with every high score in the diagonal, ranging between .885 (in the variable "Developing interventions related to ventilation") and .977 (in the variable "Ability to mobilize knowledge"), suggesting the inclusion of all variables in the factor analysis.

\section{Factor extraction}

For the purposes of factor extraction, instead of the common factor analysis, we performed the principal components analysis since it allowed for a greater data reduction, less complexity and clearer interpretation. The latent root (eigenvalue) criterion was applied, i.e. every individual factor explained the variance of at least one other variable, if that factor was maintained for interpretation. Only eigenvalues $\geq 1$ were considered to be significant.

The Kaiser criterion suggests the extraction of five factors: the first factor had an eigenvalue of 6.09, explaining around $23.40 \%$ of the total variance; the second had an eigenvalue of 3.14, explaining around $12.00 \%$ of the total variance; the third had an eigenvalue of 2.82, representing around $10.80 \%$ of the total variance; the fourth had an eigenvalue of 2.45 , representing around $9.40 \%$ of the total variance; and the fifth had an eigenvalue of 2.08, representing around $8.00 \%$ of the total variance. Together, these five factors explained $63.87 \%$ of the total variance.

We used the Scree test criterion to analyze component dispersion and determine the optimal number of factors to be extracted. We observed that, while determining these five factors, much variance could be lost; thus, we interrupted factor extraction at this point, which corroborates the abovementioned results of the Kaiser criterion.

\section{Factor rotation}

Before factor rotation, we analyzed the proportion of the variance for each variable which was explained by the extracted components (commonalities). Table 2 
shows that the five extracted factors explain most of the variance for the variables included in the analysis, with the exception of four variables with values very close to .50 which were kept for further analysis.

After analyzing the commonalities, we examined the factor loadings of each variable in relation to the extracted components. Through the component matrix, we identified nine variables with high coefficients $(>.40)$ in more than one factor. This suggests the use of rotations to better express factor significance.
Through a Varimax orthogonal rotation, the initial set containing all variables was divided into subsets with a greater degree of interdependence in order to simplify the factors and the corresponding loadings. This allowed us to better interpret the empirical results, while maintaining their statistical properties (Schwab, 2007).

Table 2 also illustrates the clear relationship between the observed variables and the five extracted factors. There was no cross-loading, with .45 being defined as the factor loading ensuring significance for each variable.

Table 2

Matrix of the factor analysis with Varimax rotation and Kaiser normalization for five factors $(N=458)$

\begin{tabular}{|c|c|c|c|c|c|c|}
\hline \multirow{2}{*}{ Variables } & \multicolumn{5}{|c|}{ Factors } & \multirow{2}{*}{ Commonalities } \\
\hline & 1 & 2 & 3 & 4 & 5 & \\
\hline 8 & .714 & & & & & .600 \\
\hline 9 & .678 & & & & & .617 \\
\hline 6 & .670 & & & & & .558 \\
\hline 12 & .655 & & & & & .601 \\
\hline 11 & .649 & & & & & .585 \\
\hline 25 & .649 & & & & & .614 \\
\hline 17 & .639 & & & & & .550 \\
\hline 7 & .630 & & & & & .529 \\
\hline 10 & .604 & & & & & .536 \\
\hline 26 & .559 & & & & & .534 \\
\hline 16 & .480 & & & & & .530 \\
\hline 5 & .479 & & & & & .455 \\
\hline 18 & .475 & & & & & .482 \\
\hline 4 & .454 & & & & & .436 \\
\hline 14 & & .861 & & & & .899 \\
\hline 13 & & .833 & & & & .858 \\
\hline 15 & & .784 & & & & .796 \\
\hline 23 & & & .815 & & & .831 \\
\hline 22 & & & .789 & & & .810 \\
\hline 24 & & & .596 & & & .671 \\
\hline 21 & & & & .811 & & .782 \\
\hline 20 & & & & .810 & & .781 \\
\hline 19 & & & & .617 & & .629 \\
\hline 1 & & & & & .839 & .754 \\
\hline 2 & & & & & .708 & .673 \\
\hline 3 & & & & & .542 & .493 \\
\hline
\end{tabular}

Note. Eigenvalues $<.45$ were omitted and the variables were grouped by loadings in each factor.

After the rotation was performed and a satisfactory factor solution was obtained, we determined the factor significance according to the interpretation of the factor loading pattern for the variables. The variables with the highest loading had a greater influence on the designation assigned to each factor (Field, 2009). By doing this, we divided the
EGPSA into five factors: the first factor includes the variables (14) related to the Recognition and Decision dimension; the second includes the variables (3) related to the Intervention dimension; the third includes the variables (3) related to the Technical-Practical dimension; the fourth includes the variables (3) related to the Attitudinal dimension; 
and the fifth includes the variables (3) related to the Cognitive dimension.

\section{Internal consistency of the EGPSA}

In order to analyze if the complete set of variables in the EGPSA was related to the gains perceived by students, we used Cronbach's alpha (Table 3) to test the mean correlation between the proposed variables. All variables showed a high correlation with the total scale, which resulted in a high alpha value (.951). Additionally, since all variables contributed to a good alpha value, the scale could be negatively affected if any of them were deleted, with the exception of variable 1 ("Theoretical knowledge"), which maintained the total alpha value.

Table 3

Homogeneity statistics of the variables and Cronbach's internal consistency coefficient for the total EGPSA $(N=458)$

\begin{tabular}{ccccc}
\hline Variables & Mean & Standard Deviation & Corrected item-total correlation & Alpha value if item deleted \\
\hline 1 & 4.26 & .51 & .440 & .951 \\
2 & 4.32 & .50 & .573 & .950 \\
3 & 4.19 & .47 & .543 & .950 \\
4 & 4.18 & .48 & .588 & .950 \\
5 & 4.21 & .49 & .607 & .950 \\
6 & 4.14 & .54 & .663 & .949 \\
7 & 4.29 & .57 & .581 & .950 \\
8 & 4.19 & .55 & .665 & .949 \\
9 & 4.21 & .55 & .698 & .949 \\
10 & 4.17 & .56 & .679 & .949 \\
11 & 3.97 & .56 & .702 & .949 \\
12 & 4.08 & .55 & .700 & .949 \\
13 & 4.31 & .51 & .667 & .949 \\
14 & 4.32 & .50 & .674 & .949 \\
15 & 4.28 & .52 & .672 & .949 \\
16 & 3.98 & .62 & .658 & .949 \\
17 & 3.89 & .70 & .681 & .949 \\
18 & 4.06 & .51 & .656 & .949 \\
19 & 3.98 & .65 & .632 & .949 \\
20 & 4.17 & .55 & .577 & .950 \\
21 & 4.17 & .57 & .556 & .950 \\
22 & 4.19 & .53 & .660 & .949 \\
23 & 4.22 & .55 & .651 & .949 \\
24 & 4.08 & .52 & .717 & .949 \\
25 & 3.99 & .62 & .704 & .949 \\
26 & 4.02 & .55 & .674 & .949 \\
\hline
\end{tabular}

Note. Cronbach's alpha (26 items): .951

After analyzing the internal consistency coefficient for the total EGPSA, we considered it to be appropriate to also analyze each dimension separately. The alpha values for each dimension remained high (factor 1 : .927; factor 2: .699; factor 3: .930; factor 4: .797; factor 5: .866), which indicated a good internal consistency. The inter-factors and item-total correlations were high and statistically significant $(p<.001)$, with the lowest correlation occurring between the Cognitive and Attitudinal dimensions (.437), and the highest correlation between the Recognition and Decision and the Technical-Practical dimensions (.707). The inter-factors correlation with the total of the scale was higher in the Recognition and Decision dimension (.967), and lower in the Cognitive dimension (.701). 


\section{Validation of the factor analysis}

Given the impossibility of applying the EGPSA to an entirely new sample and since every result of a factor analysis should be validated, we divided the sample into two subsamples (A and B), which we obtained through the method of sample randomization available in SPSS ${ }^{\circledR}$. In this way, we divided the original sample into two subsamples, with 229 respondents each, and reanalyzed the factor models. Then, we compared both subsamples.

As regards scale adequacy, both subsamples had high scores in the Kaiser-Meyer-Olkin measure (subsample A scale: .939; subsample B scale: .923) and statistically significant values in Bartlett's test of sphericity (subsample A scale: $\mathrm{X}^{2}=3456.931$ with $p<.001$; and subsample B scale: $\mathrm{X}^{2}=4053.060$ with $p<.001$ ). In both subsamples, the Kaiser criterion suggests that, similarly to the original scale, five factors must be extracted. Together, these five factors explain most of the variance of the original variables, with $63.28 \%$ for subsample A scale and $66.35 \%$ for subsample B scale. After applying Varimax rotation to both subsamples and setting . 45 as a significant factor loading for each variable, we observed that the scale in both subsamples was quite similar concerning the factor loadings and commonalities in the five factors. We also found a factor cross-loading in variable 24 ("Psychomotor abilities related to emergency interventions") in subsample B scale with close proximity (.488 vs. .599) between factors one and four. However, this makes it mathematically appropriate to factor 4 , as in the original scale.

Both internal consistency coefficients were high and very close to the original scale: .950 and .953 for subsample A scale and subsample B scale, respectively. Since all variables contributed to a good alpha value, the scale could be negatively affected if any of them were deleted, with the exception of variable 1 ("Theoretical knowledge"), from subsample B scale, which maintained the total alpha value.

\section{Descriptive results of the EGPSA}

The measures of central tendency and dispersion applied to the total scale and each of its dimensions showed that students perceive simulated practice using high-fidelity simulators as being very important in their teaching/learning process and bringing about effective gains. With a mean score that could range from one to five, the Attitudinal dimension showed the highest mean score (4.301), and the Recognition and Decision dimension the lowest one (4.100). Analyzing the EGPSA as a whole, with a mean score of 4.151 and a median of 4.076 associated with the percentiles (P25: 3.92; P50: 4.07; P75: 4.34), the perception of most students was that they had improved considerably.

\section{Discussion}

In nursing education, simulated practice is one of the main components of the academic curriculum, in which students feel that they acquire the necessary skills to cope with the clinical settings with greater self-confidence, autonomy and satisfaction.

A scale with 26 statements, which resulted from the initially proposed 30-item instrument, was applied to a population of 4th-year nursing students, during the curricular unit of Emergency Nursing.

Since it was impossible to assess separately each gain perception due to their specificity and the high number of correlations (325) of the scale under analysis, we focused the analysis on the students' perception of the dimensions related to the overall gains. We performed an exploratory factor analysis in order to identify these dimensions by summarizing data, grouping together the different specific variables, and interpreting and describing the latent dimensions, with minimal information loss.

The database used in this study proved to be suitable for the proposed objectives, with a ratio of 17 observations for each analyzed variable, ensuring robust and reliable results significantly above the recommended minimum values (Hair et al., 2010). Furthermore, the Kaiser-Meyer-Olkin measure, with a value ranging from 0.90 to 1 , showed an excellent sampling adequacy (Beavers et al., 2013).

We used the Kaiser criterion to extract the factors and determine the number of factors that best represented the correlation pattern between the observed variables. This criterion suggests that the extraction of five factors with eigenvalues greater than 1 contributed to explaining the variance in the original variables. We also used the Scree test and the cumulative variance criterion, in which we adopted $60.00 \%$ as the acceptable threshold (Hair et al., 2010). We performed the factor rotation in order to facilitate the interpretation of the empirical results, without 
affecting their statistical properties (Schwab, 2007). We used the Varimax orthogonal rotation to minimize the number of variables with a high loading on each factor (Pallant, 2011). To interpret the role played by each variable on the definition of each factor, we assumed the value of $>.45$ as the minimum acceptable factor loading.

After validating the scale, we found a high correlation between almost all variables and the total scale, with a good reliability (alpha $=.951$ ), which indicates that the scale measures the students' perceptions of the gains from simulated practices.

The correlation between the factors and the total scale is higher in the Recognition and Decision dimension (.967) and lower in the Cognitive dimension (.701), which suggests that leadership and the ability to diagnose and define priorities in critical patients significantly influence the perceived gains from high-fidelity simulation. This is consistent with daily clinical practice, in which nurses are required to make decisions, plan care provision, act ethically, manage the unit, and supervise care provision and the multiprofessional team (Gelbcke, Souza, Sasso, Nascimento, \& Bulb, 2009). On the other hand, despite the good correlation between the acquired theoretical knowledge and the impact of simulation on the student's learning, it is necessary to focus more on reflection on action, bringing into the simulation experience the topics discussed in the classroom.

The factor models of both subsamples, resulting from the division of the original sample into two subsamples, were identical to the original one, showing good psychometric properties. Thus, we believe to have obtained stable results with the initial sample.

Students considered the Attitudinal dimension of assessing and reflecting on their actions and developing self-criticism as the most obvious gain from the high-fidelity simulation, while considering the Recognition and Decision dimension as the least obvious one.

Despite the excellent sampling adequacy and the good results obtained from the factor analysis validation through randomization, some of the limitations of this study were the fact that simulated clinical experiences are specifically targeted at emergency care and that factor analysis was not validated using a completely different sample.

\section{Conclusion}

Our study aimed at describing the construction and validation of a scale that could be used to assess the gains perceived by nursing students after their clinical experience using high-fidelity simulators.

The final version of the EGPSA was composed of 26 variables divided into five factors.

The sampled students perceive simulation using high-fidelity simulators as being very important for the development of their recognition and decision-making skills in the different clinical settings, their psychomotor skills and ability to intervene, their self-criticism and self-reflection on action, and their ability to improve and mobilize knowledge.

The EGPSA shows a high reliability and validity; thus, it has the potential to analyze/assess nursing students' perceptions of the gains from high-fidelity simulation. It has good psychometric and conceptual properties, and it is a simple and easy to answer instrument.

Since it was applied only to $4^{\text {th }}$-year students, it should be applied also to students attending other levels of education, nursing schools and graduate degrees, where simulated clinical practices with high-fidelity simulators are used as a teaching/learning strategy.

We believe that further studies will contribute to improve the reliability of the EGPSA as a research instrument.

\section{References}

Baptista, R. C., Martins, J. C., Pereira, M. F., \& Mazzo, A. (2014). High-fidelity simulation in the nursing degree: Gains perceived by students. Revista de Enfermagem Referência, 7(1), 131-140.

Barroso, I., Vilela, I., Rainho, C., Correia, T., \& Antunes, C. (2008). Adaptação para a língua portuguesa do questionário KEZKAK: Instrumento de medida dos fatores de stresse dos estudantes de enfermagem no ensino clínico. Revista de Investigação em Enfermagem, 17(1), 34-40.

Beavers, A. S., Lounsbury, J. W., Richards, J. K., Huck, S. W., Skolits, G. J., \& Esquivel, S. L. (2013). Practical considerations for using exploratory factor analysis in educational research. Practical assessment, research \& evaluation. Retrieved from http://pareonline.net/getvn.asp?v $=18 \& n=6$

Butler, K. W., Veltre, D. E., \& Brady, D. S. (2009). Implementation of active learning pedagogy comparing low-fidelity simulation versus high-fidelity simulation in pediatric nursing education. Clinical Simulation in Nursing, 5(4), e129-e136. doi: 10.1016/j.ecns.2009.03.118 
Fabrigar, L. R., Macdonald, T., \& Wegener, D. T. (2005). The structure of attitudes. In Albarracin, D., Johnson, B., \& Zanna, M., (Orgs.), The bandbook of attitudes and attitude change (pp.79-124). Mahwah, NJ: Erlbaum.

Field, A. (2009). Discovering statistics using SPSS (3 $3^{\text {a ed.). }}$ Londron, England: Sage.

Flo, J., Flaathen, E. K., \& Fagerström, L. (2013). Simulation as a learning method in nursing education: A case study of students' learning experiences during use of computerdriven patient simulators in preclinical studies. Journal of Nursing Education and Practice, 3(8), 138-48. Retrieved from http://www.sciedu.ca/journal/index.php/jnep/article/ view/1841/1333

Gelbcke, F. L., Souza, L. A., Sasso, G. M., Nascimento, E., \& Bulb, M. B. (2009). Liderança em ambientes de cuidados críticos: Reflexões e desafios à Enfermagem Brasileira. Revista Brasileira de Enfermagem, 62(1), 136-139.

Hair, J. F., Black, W. C., Babin, B. J., \& Anderson, R. E. (2010). Multivariate data analysis. Retrieved from http://210.212.115.113:81/Amarnath\%20Bose/Lib/ Multivariate\%20Analysis/HairBlackBabinAnderson_758. pdf

Holli, S. (2015). Recent graduates' perspective on the efficacy of nursing simulation laboratory experiences (Doctoral dissertation, Walden University). Retrieved from http:// scholarworks.waldenu.edu/cgi/viewcontent.cgi?article $=1$ $554 \&$ context $=$ dissertations

Kameg, K., Howard, V. M., Clochesy, J. M. Mitchell, A. M. \& Suresky, J. M. (2010). The impact of high-fidelity human simulation on self-efficacy of communication skills. Issues In Mental Health Nursing, 31(5), 315-323.

Karagozoqu, S. (2009). Nursing students' level of autonomy: A study from Turkey. Nurse Education Today, 29(2), 176-87.
Kelly,S. (2014).Evaluation methodsusedinsimulation: Asurvey of faculty and student perceptions in an undergraduate nursing program (Doctoral dissertation, University of Pittsburgh). Retrieved from http://d-scholarship.pitt. edu/23513/1/ETD_Kelly_Susan_12-10-14_Revisions.pdf

Martins, J. C., Mazzo, A., Baptista, R. C., Coutinho, V. R., Godoy, S., Mendes, I. A., \& Trevizan, M. A. (2012). The simulated clinical experience in nursing education: A historical approach. Acta Paulista de Enfermagem, 25(4), 619-625.

Montenery, S. M., Walker, M., Sorensen, E., Thompson, R., Kirklin, D., White, R., \& Ross, C. (2013). Millennial generation student nurses' perceptions of the impact of multiple technologies on learning. Nursing Education Perspectives, 34(6), 405-409. doi: $10.5480 / 10-451$

Pallant, J. (2011). SPSS survival manual: A step by step guide to data analysis using SPSS ( $4^{\text {th }}$ ed.). Crows Nest, Australia: Allen \& Unwin.

Sanford, P. G. (2010). Simulation in nursing education: A review of the research. The Qualitative Report, 15(4), 1006-1011. Retrieved from http://www.nova.edu/ssss/QR/QR15-4/ sanford.pdf

Schwab, A. J. (2007). Data analysis and computers II. Retrieved from http://www.utexas.edu/courses/schwab/sw388r7_ spring_2007/SW388R7_Syllabus_Spring_2007.pdf

Swenty, C. F., \& Eggleston, B. M. (2010). The evaluation of simulation in a baccalaureate nursing program. Clinical Simulation in Nursing, 7(5), e181-e187.

Teixeira, I. N., \& Felix, J. V. (2011). Simulation as a teaching strategy in nursing education: Literature review. Interface Comunicação, Saúde, Educação, 15(39), 1173-83. Retrieved from http://www.scielo.br/pdf/icse/2011/nahead/aop3011 
